\title{
A parallel corpus approach to investigating semantic change
}

\author{
Kate Beeching \\ University of the West of England, Bristol, UK
}

\begin{abstract}
Traugott and Dasher (2002) suggest that the frequency of certain contextual interpretations of an item can end up by eclipsing its original sense. Pragmatic markers, lying at the extreme right of the spectrum of semantic change where the core meaning is almost entirely bleached, are often multifunctional, serving both turn-taking and modal functions or, as in the case of quand même, the focus of this study, both an adversative and a relational function. This chapter explores the potential of parallel corpora as a means of demonstrating that semantic change has indeed occurred. If English translators systematically select a particular functional equivalent, this may prove to be a sound test for semantic change.
\end{abstract}

Keywords: semantic change, parallel corpora, quand même, implicature, polysemy

\section{Translation and linguistic change}

The relationship between translation and linguistic change has become the focus of renewed interest in recent years, both in regarding translation as a source of contact-induced change (McLaughlin 2011) and in the study of translations as a means of tracking change. Van Hoeke and Goyens (1990) point out that semantic change is generally asserted on the basis of context but propose that translation can be a useful tool in the detection of such change. Their particular study focuses on Latin Source Texts (STs), namely Cicero's De Inventione and Rhetorica ad Herennium, and the successive translations of these texts into French Target Texts (TTs). The ST is thus used as the tertium comparationis and the French translations compared as a means of exploring semantic change from an onomasiological viewpoint. Van Hoeke and Goyens note the evolution of particular lexemes (CASU 'by chance', translated successively as par cas, par aventure and par hasard), 
lexical chain reactions (such as that between rien, chose and cause) and the gradual obligatorification of the definite article from Old to Modern French. Taking a similar approach, Lehiste (1999) studied six Estonian translations of Schiller's An die Freude from 1813 to 1959, focussing on the Estonian equivalents found for German grammatical features which do not appear in Estonian: definite and indefinite articles, the rendering of the future tense and the expression of the passive voice. Lehiste claims that the successive translations show a gradual decrease of German in the language of the translations. Though the first two translators studied are native speakers of German and their translations might perhaps be considered to be less reliable than the others, a shift in the direction of an Estonian 'norm' is detectable in the final four.

Both studies highlight the fact that, in using translation as a means of searching for language change, the translation analyst has to contend with the possibility of:

a. error

b. translationese (Van Hoeke \& Goyens (1990:124) refer to the "reliability of the translation: how can we be sure that, while transposing the ST, the translators were not consciously or unconsciously influenced by the SL?")

c. trends in translation practice

d. stylistic and idiolectal preferences on the part of the translator.

The present study differs from those previously mentioned in focussing on the semasiology of a single French lexeme quand même and the translations of this lexeme into English across time. It thus uses TL versions to assess degrees of polysemy in the SL (rather than using successive TL versions of items in a single ST to assess the evolution of the TL). It takes a quantitative parallel corpus approach, regarding the evolution of polysemies to be a question of distributional frequency.

The chapter is structured in the following way: Section 2 highlights the potential of translation as a means of tracing semantic change specifically with relation to pragmatic markers. The way in which markers develop hedging and other uses is set within the framework of Traugott and Dasher's (2002) Invited Inferencing Theory of Semantic Change and the research question concerning the usefulness of a parallel corpus approach is posed. Section 3 describes the parallel corpus approach and outlines a rationale for, and the difficulties in locating, corpora suitable for the study of pragmatic markers. Section 4 proposes a Peircean framework for the understanding of pragmatic meaning, explores the ways in which pragmatic meaning is captured in translation and airs thorny problems to do with the degree of semanticisation of pragmatic implicatures. Section 5 presents the case study on quand même, tracing its historical development from a conjunction to an adverbial and thence to a pragmatic marker with both adversative and 
relational interpretations. The usefulness of parallel corpora in supporting a lone researcher's contextual interpretation and assertion that quand même has developed a relational or hedging meaning is proposed. Section 6 provides details of, and evidence from, the three parallel corpora investigated, charting the translation equivalents for quand même found in these corpora. A discussion section evaluates the evidence, drawing on the Peircean framework to elucidate the interface between context, meaning and linguistic form. In the Conclusions in Section 7, the merits of the parallel corpus approach to the investigation of semantic change are weighed up against the inherent difficulties posed in finding exact equivalence in translation.

\section{Translation and the diachronic evolution of pragmatic markers}

As Aijmer et al. (2006:111) argue, the usefulness of translation as a means of investigating aspects of a SL has been convincingly argued elsewhere. They claim that translation is particularly valuable for pragmatic markers because of their "underspecified core meaning and their polysemous nature".

The development of hedging and other uses of pragmatic markers can be most profitably examined within the framework of Traugott and Dasher's (2002) Invited Inferencing Theory of Semantic Change (IITSC). Building on Gricean pragmatic theories relating to conversational implicature (which are gone into in greater detail in Section 4), the IITSC foregrounded the role of conversational interaction and speaker relationships in semantic change. The original Meaning (M1) of a lexeme $\mathrm{L}$ with a conceptual structure $\mathrm{C} 1$ is used pragmatically by speakers in such a way that it acquires a slightly different conceptual structure C2. If L is frequently used in such a way, it may, through constant contiguity on the syntagmatic chain, become routinised in this new meaning and become M2 - a new coded meaning of L.

From a synchronic viewpoint, pragmatic markers are well-known, amongst other things, to have little or no propositional meaning, to be multifunctional and operate on several linguistic levels, to be a feature of oral rather than written discourse, to be associated with informality, to appear with high frequency, and to be stylistically stigmatised (Brinton 1996:33-36).

These features pose particular problems for those studying the multifunctionality of the forms and their diachronic evolution; the course of semantic change is generally acknowledged as passing through 'bridging contexts' (Evans \& Wilkins 2000), in which the term in question can be ambiguously interpreted as both M1 and M2.

The present study aims to explore the ways in which parallel corpora can help the scholar of semantic change to assert that a shift has indeed occurred at a particular point in time. 


\section{The parallel corpus approach}

The advantages of a corpus approach are well-known and are particularly apposite in the case of pragmatic markers as their uses are not easily amenable to intuition, to grammaticality judgements or even to realistic assessments of who uses them, when and why. Using corpora allows the researcher to see usage in context, and to uncover regularities and patterns of usage, with respect to the class, age and educational background of speakers, and to text types and genres. Parallel (or translation) corpus approaches are less well-documented, though a spate of recent studies indicate their usefulness in translation studies (Granger et al. 2003; Olohan 2004; Anderman \& Rogers 2008). They have been applied, using the Oslo Multilingual Corpus, in the exploration of the function of pragmatic markers in synchrony, in Aijmer and Simon-Vandenbergen (2003), using the English-Swedish Parallel Corpus and the Triptic Corpus for Dutch, to explore the equivalents of well in Swedish and Dutch and, in Aijmer (2007), to study translations of oh in Swedish and German (and to items in Swedish which are translated oh in English). To my knowledge, a parallel corpus approach has not been employed to explore the diachronic evolution of the senses and functions of pragmatic markers, and in particular to trace the evolution of quand même in French.

Pragmatic markers, as we have seen, are a feature of oral rather than written discourse. Though spoken corpora for French are gradually becoming more available for the researcher (the Beeching Corpus and the Corpus du Français Parlé Parisien are accessible online - further information and the URLs for all the corpora mentioned are provided in the 'Corpora consulted' list at the end of the chapter), spontaneous conversational data which have the highest rates of occurrence of markers are rarely, if ever, translated. This suggests a serious limitation in the extent to which parallel corpora may be used to explore their evolution. We can look at translations of literary and other fictional works which contain dialogue - but these are of course scripted and, given the informality and, at times, stigmatised nature of markers, occurrences may be rarer in written works than we would like. Subtitling offers potential but most films are scripted and tend not to include the number of pragmatic markers which we see in spontaneous everyday conversation.

One of the other remarkable characteristics of pragmatic markers is that they have little or no propositional meaning. When texts containing markers have been translated, markers may be simply omitted in the translation as they bring no new informational content. This is particularly the case in film subtitles where there is pressure on space (though see Guillot 2010 on this issue). Although the omission of any translation of the pragmatic marker is interesting in itself (indicating 
perhaps the desemanticisation of the marker), it does not help the researcher who is intent on demonstrating the evolving polysemies or potential interpersonal functions of an item.

\section{Context and meaning, Gricean GCIs and PCIs}

Going beyond the Saussurean dyad of the signifier and the signified, Peirce (1931$35,1958)$ proposed a triadic approach to semiology, comprising:

- a "representamen" (an expression, a vehicle),

- an "object" (that which is represented) and

- an "interpretant" (an interpreting thought, or further equivalent sign evoked in the mind of the comprehender by the original sign).

A "sign" then is indexical - it points to a potential meaning but is dynamically interpreted in a particular context. As Hansen (2008: 46-51) argues, the inclusion of an interpretant incorporates a pragmatic dimension and allows for language variation and polysemy. The question of contextual interpretation provides a link with translation: translations of individual lexemes are, generally speaking, situated in stretches of text with both co-text and context which support the interpreting thought and inform (or constrain) the translational equivalent offered to the receiver of the translated text.

Being contextually-bound, the interpretant (and resulting translation) may draw on what Grice (1975) terms either a Generalised or Particularised Conversational Implicature (GCI or PCI). GCIs arise irrespective of the context in which the item occurs. They require a specific type of context to be cancelled. Only a very literal-minded hearer would reply to "Can you pass the salt?" by saying "Yes, I can (physically) reach over to the salt and I can (physically) pass it over to you - but I won't!". The conventionalisation of the modal auxiliary in request formulas makes it the default interpretation in most situations. PCIs, on the other hand, are inferences which are derived from a particular context. This is illustrated by Hansen and Waltereit (2006: 261) through a variation of Grice's (1975) standard example, reproduced in (1):

(1) (Two students having lunch in the university cafeteria)

A: Professor $\mathrm{X}$ is an old bag.

(Professor X passing by behind A)

B: Can you pass the salt?

As Hansen and Waltereit remark (2006: 261): 
The apparent flouting of Relation in B's utterance, with its attendant PCI, is clearly in the foreground of the message and supersedes the request interpretation by GCI (let alone the literal interpretation).

The flouting of Grice's Maxim of Relation leads to the interpretation that B is rapidly changing the topic of conversation - and the hearer will cast around for a reason for this. Such flouting strategies may generalise - in my own family, the formula "Hmm. Nice weather for the time of year" is used generically and ironically to mean "You have said something inappropriate" and "Time to change the topic of conversation".

Sweetser (1990) drew our attention to the ubiquity and universality of the connection between pragmatic ambiguity, lexical polysemy and semantic change. A problem which arises in relation to the possibility of using translation equivalence as a means of disambiguating evolving polysemies is that the same process of pragmatic ambiguity, lexical polysemy and semantic change can occur cross-linguistically in relation to a particular lexeme. "Can you pass the salt?" can have the same literal interpretation, GCI and PCI (to my knowledge) in French, German and Spanish and most likely in other, genetically less related, languages as well. In those cases, the translation equivalent is unlikely to shed light on the evolving polysemy of the term in L1.

What we are investigating here is the way in which a PCI, associated with a particular lexeme, becomes encoded in the language through habitual contiguity on the syntagmatic chain. Traugott and Dasher (2002) suggested that such change occurs via a GCI, in other words there is an implicational hierarchy from $\mathrm{PCI}>\mathrm{GCI}>$ coded meaning. This position is, however, challenged by Hansen and Waltereit (2006) who claim that it is neither theoretically nor empirically tenable. Their alternative proposal underlines the fact that PCIs are in the communicative foreground of a message while GCIs are in the background. In order to become coded, GCIs must pass through a foregrounded PCI stage. So either a PCI semanticises directly, or a PCI turns into a GCI but is not fully semanticised, or a GCI semanticises, but only after being foregrounded as a PCI. An interesting facet of their argument (2006:264) is that there are good reasons for implicatures not to semanticise, as they frequently serve purposes of face saving and/or hedging. The required indirectness is only maintained if the suggested meaning remains implicit.

The problem of contextual renderings for semantic studies was also raised by Dyvik (1998:52) who describes the translational relation as being one which pertains between situated texts, not a relation between abstract linguistic expressions. It interrelates parole rather than langue items. He makes a sharp distinction between semantic characteristics and pragmatic ones such as the context of utterance, the purpose of the utterance and other kinds of background knowledge: 
Semantic properties are properties of linguistic expressions seen as types, not only as token in texts. In order to use translations as a source of information about semantics, we therefore need to extricate the contribution that contextual factors such as these make to the translational relation from the contribution made by correspondence relations between words and phrases seen as types. That is, the translational relation we are interested in isolating is not the one between texts or parole items, but the one between linguistic expressions or 'signs' seen as types, that is, between langue items as they occur in grammars or dictionaries.

Dyvik's aims are to find a translational basis for semantics and his approach is well-grounded and detailed. However, from the point of view of semantic change, it is precisely the new contextual interpretation which is important. The M2 of quand même frequently does not appear in dictionaries. It seems that, not only might translations show langue senses but also new senses which emerge in parole. The question which then arises is the extent to which the meaning thus rendered is a contextually conditioned one (i.e. part of pragmatics) or whether it is a coded one (part of semantics).

Here we enter another area of controversy: the minimalist/maximalist debate. Do we consider a particular lexeme to have a 'core meaning' which may be overlaid with contextual side-effects (peripheral meanings) - the minimalist position? Or do we consider each new function to be a new sense and the term to be thus polysemous - the maximalist position? Hansen (1998: 88) invokes Occam's razor, the principle of not proliferating meanings beyond what is reasonable, and recommends a type of modified methodical minimalism. In other words, as Aijmer (2002:21) puts it, we arrive at a position "where discourse particles can have different functions which are related to a core or prototype in a polysemous way". This position allows for variation and change and for the possibility that items may indeed ultimately shift to entirely unrelated senses.

While unifying and parsimonious explanations are intellectually satisfying, they shed little light on the process of semantic change. As Aijmer says (2002: 20-21):

The core meanings which have been proposed tend to be abstract, very general or too summary. It is therefore difficult to see how this approach would explain the relationship between the meaning of the particle and its functions on the textual and interpersonal levels.

I hope to contribute to this debate, drawing on the pragmaticalisation and translation equivalence of quand même by way of a case study. 


\section{The case of quand même}

In contemporary French, the translation equivalent of quand même in English is generally given as 'all the same' or 'even so'. It has thus a canonically adversative or concessive sense. It is classified in dictionaries, for example the Oxford Hachette, under the head-word quand as an adverbial phrase and it is rarely, if ever, used as a conjunction.

A typical example might be:

(2) Ils étaient occupés mais ils nous ont quand même rendu visite.

'They were busy but even so they came to visit us.'

(Oxford Hachette 1994:661)

Historically, the expression quand même originated as a fusion of the temporal conjunction quand ('when') with the reinforcer mesme/même 'even', and meant 'at the very moment when'. The concessive sense of 'although' developed from this, and, though it is still written as two words, the form coalesced as an inseparable unit as it grammaticalised and moved from a conjunctival to an adverbial usage.

Beeching (2005) provided a (non-parallel) corpus analysis of the evolution of quand même drawing on the large literary corpus FRANTEXT (1500-2000) and examples from the ESLO (Enquête Sociolinguistique d'Orléans) Corpus and Beeching Corpus of spontaneous spoken French.

Table 1 shows the rise in the incidence of quand même in the theatrical works in FRANTEXT from 1500-2000. Note the massive increase in the rate of occurrence between 1900-1949 and 1950-2000. Increase in frequency is a strong indicator of semantic change.

Table 1. Rate of occurrence of quand même per 10,000 words in the genre 'Théâtre' in the FRANTEXT across the centuries (adapted from Beeching 2005: 165)

\begin{tabular}{lccl}
\hline Period & $\begin{array}{l}\text { Occurrences of } \\
\text { quand mesme }\end{array}$ & $\begin{array}{l}\text { Occurrences of } \\
\text { quand même }\end{array}$ & $\begin{array}{l}\text { Rate of occurrence } \\
\text { of quand mê(s)me } \\
\text { per 10,000 words }\end{array}$ \\
\hline $1500-1599$ & 4 & 0 & 0.044 \\
$1600-1699$ & 34 & 17 & 0.139 \\
$1700-1799$ & 0 & 20 & 0.08 \\
$1800-1899$ & 0 & 26 & 0.103 \\
$1900-1949$ & 0 & 111 & 0.394 \\
$1950-2000$ & 0 & 145 & 1.246 \\
\hline
\end{tabular}


Example (3) illustrates the way in which quand mesme/quand même was used, up to the nineteenth century, exclusively as a subordinating conjunction and accompanied by a conditional tense. The sense can be derived from the context and can be translated as 'even though' or 'although'. This conjunctival, concessive, use is no longer current in contemporary French, and has been assumed by bienque or quoi que.

(3) Je prépare un discours qui la pourroit toucher

Quand mesme au lieu d'un coeur elle auroit un rocher.

(FRANTEXT Corpus: Du Ryer, Pierre, Les vendanges de Suresne, 1636, page 62 , Acte 1 , scène iv (vi))

'I'm preparing a speech which should be able to touch her

Even though she had a rock in place of a heart.'

Moeschler and de Spengler (1981) describe the usage of quand même in contemporary French as having a logical, concessive, value based on a causality relation, which may be expressed as $p$ mais quand même $q$ ( $p$ but all the same $q$ ).

Example (4), shows the adverbial 'all the same' usage (without the accompanying mais 'but') in the Beeching Corpus of spontaneous spoken French.

(4) Ce n'est pas une ville qui bouge/ c'est une ville qui a quand même un cinéma la saison estivale pendant la saison estivale et deux boîtes de nuit/ deux discothèques.

(Beeching Corpus 4:35-36) ${ }^{1}$

'It's not a very lively town/ it's a town which has all the same/nonetheless got a cinema in the summer season during the summer season and two night-clubs/ two discos.'

The underlying implicature of 'not a very lively town' leads to an expectation that the town would be unlikely to have a cinema or a disco. The contradiction in the ensuing proposition is articulated using quand même ('all the same', 'despite one's expectations to the contrary').

This example, however, constitutes a classic example, of a bridging context. Grieve (1996) describes two modes for quand même in contemporary spoken French, an adversative 'all the same' mode and a more apologetic mode. He concludes:

1. The figures here indicate that this is interview 4 in the Beeching Corpus, lines 35-36. This convention is adopted throughout the chapter. 
This mode has a familiar tone, more spoken than the first. Robert's definition is Il faut avouer, à vrai dire, on en conviendra. To that list, one should probably add je ne devrais pas le dire mais... In speech it is a tactical gambit which, by sketching an apparent attenuation of what might be sensed as the impropriety of an affirmation, can enable the reinforcement of the latter. It facilitates what has been called la mise en acceptabilité d'une contradiction (Moeschler \& Spengler 1981: 110). That is, it offers a justification for the statement it accompanies, even a sort of excuse or apology for it. But thereby it too has an adversative quality, faint and implicit, in that it hints at contradicting an assumed objection.

(Grieve 1996:417)

Thus, quand même, regardless of the context in which it occurs, will evoke some kind of adversativity, and this is a GCI in Gricean terms. However, in some contexts it begins to have a PCI which is generalising and which has a simultaneously hedging and boosting quality (on this apparent contradiction, see Beeching 2009).

Example (4) could equally well be translated as:

'It's not a very lively town/ (but) it's a town which has at least got a cinema in the summer season during the summer season and two night-clubs/ two discos.'

M1, then, is adversative and is equivalent to 'but' or 'all the same'; M2 is relational, providing a type of excuse or apology, a justification for the statement it accompanies. The term 'relational' is used here in the lay sense of having to do with interpersonal relations (as distinct from having a propositional, adversative, sense). Other dichotomous terms which are sometimes used in the literature for such oppositions are 'textual vs. interpersonal' or 'referential vs. intersubjective'.

Example (5) illustrates this relational usage of quand même.

(5) Ça a l'air d'être une famille quand même assez riche.

'It seems to be quite a rich family actually.'

(Beeching Corpus 1:647)

There is nothing in the context of this example which might be considered to motivate a contrast or canonical, referential, adversative sense (in other words there is no $\mathrm{P}$ for a $P$ mais quand même $Q$ formulation). Quand même both hedges and boosts the utterance, but has no adversative force in a propositional sense.

We thus see the development of:

M1 adversative
$\mathrm{M} 1 / \mathrm{M} 2$

adversative/relational
M2

relational 
It is the development of adverbial uses and, in the period from 1950, of relational uses, which accounts for the huge rise in the incidence of quand même which we see in Table 1. This is demonstrated in the detailed breakdown of the evolution of conjunctival and adverbial, adversative and relational usages of quand même in Table 2.

Table 2. Number and rate of occurrences of quand mesme/quand même in the theatrical works in the FRANTEXT Corpus from 1500 to 2000 (adapted from Beeching 2005: 166)

\begin{tabular}{|c|c|c|c|c|c|c|c|c|}
\hline \multirow[t]{3}{*}{ Period } & \multicolumn{4}{|c|}{ Conjunctions } & \multicolumn{4}{|c|}{ Adverbs } \\
\hline & \multicolumn{2}{|c|}{ Concessive } & \multicolumn{2}{|c|}{$\begin{array}{l}\text { Temporal or } \\
\text { contrastive }\end{array}$} & \multicolumn{2}{|c|}{ Adversative } & \multicolumn{2}{|c|}{ Relationa } \\
\hline & $\mathrm{N}$ & $\%$ & $\mathrm{~N}$ & $\%$ & $\mathrm{~N}$ & $\%$ & $\mathrm{~N}$ & $\%$ \\
\hline $1500-1599$ & 4 & 100 & - & - & - & - & - & - \\
\hline $1600-1699$ & 47 & 92 & 1 & 2 & z- & - & - & - \\
\hline $1700-1799$ & 19 & 95 & 1 & 5 & - & - & - & - \\
\hline $1800-1899$ & 14 & 54 & - & - & 11 & 42 & - & - \\
\hline $1900-1949$ & 9 & 8 & - & - & 61 & 55 & 36 & 32 \\
\hline $1950-2000$ & 8 & 0.5 & - & _ & 64 & 44 & 72 & 50 \\
\hline
\end{tabular}

It is, however, in the spoken corpora that we find the vast majority of the relational uses and far higher rates of occurrence overall. These are shown in Table 3.

Table 3. Rates of occurrence per 10,000 words of quand même in the ESLO Corpus (1968-1971) and Beeching Corpus (1988-1991) (from Beeching 2005: 168)

\begin{tabular}{lcc}
\hline Function & Corpus ESLO & Beeching Corpus \\
\hline quand même (adversative) & $5.16(36 \%)$ & $8.21(36 \%)$ \\
quand même (relational) & $9.22(64 \%)$ & $14.90(64 \%)$ \\
Total & $\mathbf{1 4 . 3 8 ( 1 0 0 \% )}$ & $\mathbf{2 3 . 1 0 ( 1 0 0 \% )}$ \\
\hline
\end{tabular}

In seeking to differentiate between adversative and relational quand même in the spoken corpora, I had to rely on my own intuitions or translation equivalents. I adhered strictly to the following criteria:

1. Explicit adversative.

Explicit adversative uses of quand même have two conjoined clauses in which there is an explicitly expressed adversative opposition of the type (Not) P, (but) quand même Q.

2. Implicit adversative/relational.

The logical two-part structure (Not) P (but) quand même Q is absent. 
The advantage of the parallel corpus approach is that it includes translations undertaken as a naturalistic activity by a number of translators, each of whom interprets the sense of a term in context. A study of the translations of quand même might provide me with additional evidence for the fact that quand même has indeed developed a relational sense which is distinguishable from its adversative sense to support my subjective interpretation of this term.

\section{Evidence from three parallel corpora}

The corpora investigated were:

1. The INTERSECT Corpus (Raf Salkie) - this is 1,602,874-word, mixed corpus, written, and for the most part literary. The Corpus includes: articles from Le Monde and their translation in the Guardian Weekly; magazine articles and official documents from Canada; instructions for a variety of domestic appliances; technical texts about telecommunications; texts from international organisations; modern fiction; and academic textbooks.

2. A corpus of texts from the European Parliament collected by Michael Barlow for use with Paraconc - this is a spoken corpus, transcribed and translated of $1,251,033$ words

3. The OPUS (OpenSubtitles) Corpus, 1,800,000 words. This is a vast and growing corpus of sub-titled films. For further details, see Teidemann (2009).

In order to gauge the extent to which translational equivalents might give an indication of semantic shift in a broad-brush and quantitative way, terms in English were sub-divided into those that might be considered to be adversatives, such as all the same, nevertheless, still and though, intensifying expressions such as really and the emphatic use of do, and hedges and fillers such as kinda, so, you know and well. A 'zero' category tallied up the number of times that quand même was simply omitted in translation. These are charted in Table 4. A few tokens in each corpus had to be discounted as noise (where there appeared to have been misalignment in the parallel corpus or lines had been included twice). Noise rates are, however, relatively low and similar across the different corpora.

Preliminary analyses show that rates of quand même vary somewhat across the corpora. The highest rates of quand même occur in the subtitle corpus, perhaps unsurprisingly, as, of the three corpora, film subtitles might be expected to reflect spontaneous and familiar spoken usage to the greatest extent. It is perhaps more surprising that the rate of occurrence of quand même in the more literary written INTERSECT corpus outstrips that of the European Parliament (EP) corpus which 
Table 4. Translations of quand même in the INTERSECT, European Parliament and OPUS Corpora, as adversatives, intensifiers, hedges/fillers, other formulations and zero translations

\begin{tabular}{|c|c|c|c|c|}
\hline & INTERSECT & European Parliament & OPUS Sub-titles & \\
\hline \multirow[t]{2}{*}{$\begin{array}{l}\text { Rate of occur- } \\
\text { rence of quand } \\
\text { même per } \\
10,000 \text { words }\end{array}$} & $\begin{array}{l}0.51 \\
\text { ( } 82 \text { occurrences in } \\
1,602,874 \text { words) } \\
\text { Analysis conducted on } \\
78 \text { examples. }\end{array}$ & $\begin{array}{l}0.41 \\
\text { (51 occurrences in } \\
1,251,033 \text { words) } \\
\text { Analysis conducted on } \\
47 \text { examples. }\end{array}$ & \multicolumn{2}{|c|}{$\begin{array}{l}0.76 \\
(137 \text { occurrences in } \\
1,800,000 \text { words }) \\
\text { Analysis conducted on } \\
125 \text { examples }\end{array}$} \\
\hline & $\mathrm{N}$ & $\%$ & $\mathrm{~N}$ & $\%$ \\
\hline Adversative & $\begin{array}{l}54 \\
\text { all the same (13) } \\
\text { though (10) } \\
\text { just the same (5) } \\
\text { even so (4) } \\
\text { but (3) } \\
\text { still (3) } \\
\text { after all (2) } \\
\text { at the same time (2) } \\
\text { anyway (2) } \\
\text { never-theless (2) } \\
\text { none-theless (2) } \\
\text { yet (2) } \\
\text { as planned (1) } \\
\text { however (1) } \\
\text { in any case (1) } \\
\text { in spite of every- } \\
\text { thing (1) }\end{array}$ & $\begin{array}{l}24 \\
\text { nevertheless (6) } \\
\text { nonetheless (3) } \\
\text { however (3) } \\
\text { after all (3) } \\
\text { still (2) } \\
\text { but (2) } \\
\text { in any case (1) } \\
\text { having said this (1) } \\
\text { all the same (1) } \\
\text { you have to admit (1) } \\
\text { at least (1) }\end{array}$ & $\begin{array}{l}65 \\
\text { still (32) } \\
\text { anyway (14) } \\
\text { though (9) } \\
\text { all the same (2) } \\
\text { just the same (2) } \\
\text { at least (1) } \\
\text { even so (1) } \\
\text { however (1) } \\
\text { nevertheless (1) } \\
\text { nonetheless (1) } \\
\text { no matter what (1) }\end{array}$ & 52 \\
\hline Intensifier & $\begin{array}{l}9 \\
\text { does (3) } \\
\text { really (3) } \\
\text { actually (1) } \\
\text { all the time (1) } \\
\text { why not? (1) }\end{array}$ & $\begin{array}{l}8 \\
\text { do/did (5) } \\
\text { as much as (1) } \\
\text { really (1) } \\
\text { surely (1) }\end{array}$ & $\begin{array}{l}5 \\
\text { really }(3) \\
\text { I mean (1) } \\
\text { very }(1)\end{array}$ & 4 \\
\hline Hedge/filler & e & - & $\begin{array}{l}7 \\
\text { kinda }(1) \\
\text { so }(2) \\
\text { you know (1) } \\
\text { well (2) } \\
\text { what (1) }\end{array}$ & 6 \\
\hline $\begin{array}{l}\text { Other/ } \\
\text { reformulations }\end{array}$ & & & 18 & 14 \\
\hline Zero & 15 & 32 & 30 & 24 \\
\hline
\end{tabular}


is a transcription of oral proceedings. This might be attributable to the relative formality of proceedings in the European Parliament compared with the relative informality of dialogue presented in the novels in the INTERSECT corpus. The EP corpus also shows the highest rate of zero translations. A hypothesis put forward earlier was that zero translation might indicate the degree of semantic bleaching of a term. However, it might also indicate a choice on the part of the translator. If propositionally redundant, interpersonal elements were considered less important in the translation, this might be reflected in zero translation in the rendering. Zero translations are lowest in the INTERSECT Corpus which might indicate that the usage of quand même is more canonical and less bleached than in the Subtitle Corpus or, indeed, that other translatorial considerations come into play, such as the need for brevity in subtitling more generally. This highlights a substantial limitation in the use of translation corpora in judgements concerning the use of zero translations as a means of gauging the extent of desemanticization: translatorial imperatives and choices cannot be discounted as an intervening independent variable.

Individual, sometimes contextually bound, translatorial choices also make an evaluation of the plethora of equivalents selected by translators problematic. What status should, for example, be given to the translation as planned, in the EP corpus, the parallel lines for which are shown in (6):

(6) L'ONU a décidé que le désarmement des autres factions commencerait quand même dès le 13 juin.

The UN decided that it would go ahead as planned and disarm the other factions beginning on June 13.

The preceding context shows that the Khmer Rouge had categorically refused to disarm and that quand même has an adversative meaning in the context. A suitable gloss might be: 'Despite the fact that the Khmer Rouge refused, the UN decided to disarm the other factions.' As planned is contextually appropriate but is both an over- and an under-translation of quand même. It is an over-translation because, in any interpretation we might make of it, the semantics of quand même contains no reference to planning, and an under-translation since as planned contains none of the intrinsic adversativity of quand même. Referring back to the Peircean framework sketched in Section 3, the contextual background to quand même in this example produces an "interpretant" (an interpreting thought, or further equivalent sign evoked in the mind of the comprehender by the original sign) which is rendered in the translation as a particular interpretation of the "representamen". This constitutes what Dyvik (1998) might term a 'token' rather than a 'type' translation.

The analyst might decide at this point to discount the 36 hapax legomena translations (including the 'other reformulations' found in the Subtitle corpus) on 
the basis that these are 'token' and not 'type' translations. There are two problems here: one is that some hapax translations such as you have to admit have clear potential as 'type' renderings of quand même, as is clearly indicated in Robert's gloss il faut avouer ('it must be admitted') highlighted by Grieve (1996:417). The other problem is that some forms which appear more than once, such as so (which appears twice in the translations in the Subtitle Corpus) do not appear to have 'type' status. They are simply 'tokens' which occur more than once. In Examples (7) and (8), so does not so much render an interpretation of quand même as constitute a similar type of conversational filler which chimes in with the tenor of the ongoing interaction.

(7) C' est pour chez nous, quand même.

It's gonna be in our house, so ...

(8) Tu m' analyses quand même ce vomi?

So you' 11 run an analysis on that puke?

In (8), in particular, the sense of quand même is captured in Grieve's (1996:417) formulation where he describes quand même as "sketching an apparent attenuation of what might be sensed as the impropriety of an affirmation"; in other words it softens, yet reaffirms, the request that the vomit be analysed, suggesting 'despite the irksomeness of this task'. This is not captured in so despite the polysemy of this term.

What is more, the interpretation of the semantic status of the remaining, more frequently occurring, lexemes in the English translations, which also show varying degrees of polysemy, is far from clear-cut. A number of the forms can be shown to be straightforwardly adversative by reference to dictionary definitions and everyday usage: nevertheless, nonetheless, all the same, just the same, even so, however and yet appear to fall into this class, with still, after all and in any case providing a somewhat less convincing second-tier of potentially adversative usages. Other forms, however, such as but, though, anyway and really are either notoriously polyfunctional or show the same desemanticising tendency as quand même. Though, for instance, can be used both adversatively and relationally in English. In Example (9), drawn from the spoken files of the British National Corpus and commented upon, along with many other examples of relational though in Beeching (2009: 94), the P but Q logical structure is similarly absent and, though there is an implicit counter-argument concerning the quality of the vinegar, the main function of though is relational, downplaying the speaker's self-pride in the pickled onions and maintaining a self-deprecating line:

(9) Yeah, try a pickled onion Here half a one int it? Mm, the last Mm, good that vinegar though cos I sliced some onion, I like it like that, do you? 
Example (10), in which quand même has been translated using though in an extract from a novel by Céline, is a case in point:

(10) - Embrassez-moi [[quand même]] Lola. Voyons!... On n’est pas fâchés! proposai-je pour savoir jusqu'où je pourrais la dégoûter.

(M:|French-English texts|celinef.txt, Line: 1009)

"Give me a little kiss, though, Lola; don't let's quarrel," I suggested, just to see how far I could go.

(M:|English-French texts/celinee.txt, Line: N/A)

In the short concordance line provided via Paraconc, we do not know whether quand même/ though appears in a canonical adversative "P mais quand même Q" context or could be interpreted in a relational way. It might be that Lola has a cold - but that her interlocutor wishes to be kissed by her 'nonetheless' or 'despite that'. It is only by investigating the wider context that we can begin to say whether quand même and its translation equivalent though is canonically adversative or relational.

(11) “Lola, prêtez-moi je vous prie l'argent que vous m’avez promis ou bien je coucherai ici et vous m'entendrez vous répéter tout ce que je sais sur le cancer, ses complications, ses hérédités, car il est héréditaire, Lola, le cancer. $\mathrm{Ne}$ l'oublions pas!" A mesure que je détachais, fignolais des détails sur le cas de sa mère, je la voyais devant moi blêmir Lola, faiblir, mollir.

"Ah! La garce! Que je me disais moi, tiens- la bien, Ferdinand! Pour une fois que t'as le bon bout!... Ne la lầche pas la corde... T' en trouveras pas une si solide avant longtemps!..."

- Prenez! Tenez! fit-elle, tout à fait excédée, voilà vos cent dollars et foutez-moi le camp et ne revenez jamais, vous m'entendez jamais!... Out! Out! Out! Sale cochon!...

- Embrassez-moi quand même Lola. Voyons!... On n’est pas fâchés! Proposai-je pour savoir jusqu'où je pourrais la dégoûter.

Elle a sorti alors un revolver d'un tiroir et pas pour rire.

L'escalier m’a suffi, j'ai même pas appelé l'ascenseur.

"'Lola, please lend me the money you promised me, or I shall be staying the night here, and you'll have me going on and on telling you all I know about cancer and its complications and its hereditariness - because, you know, cancer is hereditary, Lola, don't forget."

As I proceeded to pick out, to toy with details of her mother's case, I saw her blench, weaken, give way before my eyes.

"Ah, the slut," I said to myself, "hold on to her tight, Ferdinand! Just once you've got her where you want her.... Don't let her go. You won't get another chance like this for a long time!" 


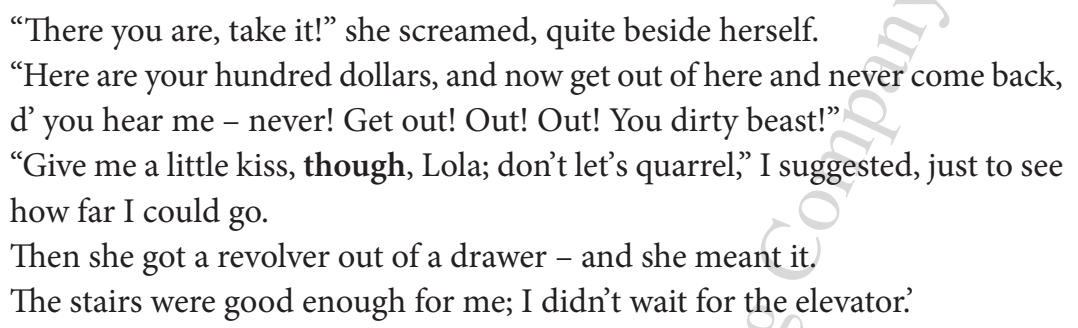

The wider context does not entirely provide the answer to the adversative versus relational dilemma. The speakers appear to be at loggerheads with each other. Quand même accompanies an imperative and can be interpreted as a hedge on what is, in the context, an outrageous request. The speaker appears to be wheedling, trying his luck, and the translator minimises the request - in the translated version, it is only a 'little kiss' that Ferdinand is asking for. This argues the case for a relational interpretation.

Quand même could, however, be interpreted in an adversative way, requesting that Lola give him a little kiss 'anyway', 'despite the fact that they are having an argument', despite the fact that she is angry with him for asking for the loan and has asked him to leave in no uncertain terms. The term is pragmatically ambiguous - and is aptly rendered by the equally ambiguous though.

Whatever the intention of Ferdinand's quand même, his request is dramatically rejected as Lola reaches for a revolver and he escapes at top speed down the stairs.

The INTERSECT written corpus has the highest rates of canonical adversative translations at $69 \%$. The occurrences of intensifying usages and zero translations do, however, provide support for the argument that quand même is desemantising and developing a relational (M2) sense. Slightly over half of the occurrences in the spoken corpora are translated using a canonical adversative (at 51\% and 52\%), with a higher proportion of zero translations in the EP corpus and more hedging and filling and PCI 'other reformulations' in the Subtitle corpus. The reason for this may be that the skopos of the EP translation is primarily referential while that of the subtitles is focused on the relationship between the characters in a dialogual context - hence the importance of retaining the colloquial spoken feel of the text via either hedging and filling expressions or different types of reformulation.

Given that, in these spoken texts, approximately $50 \%$ of the translations are non-adversative, there is considerable evidence that quand même has shifted in meaning from a strong adversative (M1) sense to M1/M2 (adversative/relational). Rates of relational translations of quand même are not as high, however, as in my analysis of the contemporary spoken corpus examples (64\%). There are two possible reasons for this: either my own analysis of the functions of quand même in the spoken corpora was biased or the genres are somewhat different. It 
is arguable on the basis of the differences between the three genres represented in the INTERSECT, EP and OPUS corpora that genre does indeed play a major role in the functions of quand même and that scripted and more formal texts tend to use it in a more canonical, adversative, manner than more spontaneous conversational texts.

Responding to the theoretical and methodological question raised concerning the pragmatic and semantic status of the relational function of quand même, we observe that really is a translation equivalent in seven cases across the three corpora. This would seem to indicate that this usage has a 'type' rather than 'token', GCI rather than PCI, status. Example (12) illustrates this usage.

(12) Lombardo, vous voulez quand même pas que je marche, non?

Mr. Lombardo, you really wouldn't want me to walk, would you?

(OPUS corpus)

Quand même 'sketches an apparent attenuation of what might be sensed as the impropriety of an affirmation' as Grieve (1996:417) puts it and 'can enable the reinforcement of the latter'. Really does not capture the attenuating force of quand même but captures its implicit adversativeness - surely might also be a suitable translation equivalent. 'You surely don't expect me to walk, do you?'. Quand même in such contexts could not be translated as however or all the same and this is a clear indication that a relational, non-adversative, sense has developed. Whether this should be considered as a contextual side-effect (and that this contextual sideeffect is picked up in translation equivalents such as really or surely or as a new sense of the expression is, however, open to debate. In the end, the polarised contextual side-effect versus 'coded meaning' debate is perhaps an arid one. It fails to capture the pragmatic-semantic continuum which is a distinguishing feature of semantic changes which occur in interactional contexts. Semanticisation by this argument is not an all-or-nothing opus operatum but a complex and nuanced modus operandi.

The role of translation in capturing contextual side-effects and in gauging degrees of semanticisation is also highly complex. Aijmer et al. (2006:111) suggest that:

Translations are rarely literal renderings of the originals, but rather reflect properties of either the source or the target language. It is obvious that there are a variety of reasons for a particular translation to be selected. Translators do not translate words and constructions in isolation but rather choose a correspondence for a linguistic element in a particular context. It follows that which words or constructions we regard as correspondences between languages ultimately depends on the analyst's own judgement. 
This view chimes in with the triadic Peircean perspective on meaning presented earlier. Meaning depends not only on a signifier and a signified but includes an 'interpretant' and when we include a SL and a TL form in the analysis, the possibilities for interpretation and factors impacting on reverbalisation complicate the picture. Figure 1 attempts to capture some of this complexity.

\begin{tabular}{|c|c|c|c|}
\hline $\begin{array}{l}\mathrm{SL} \\
\mathrm{R}>\end{array}$ & $\begin{array}{l}\text { Translator } \\
\text { interpretant }\end{array}$ & Filters & $0^{\mathrm{TL}}$ \\
\hline e.g quand même & SLcontext1 & $\begin{array}{c}\text { Audience } 1> \\
\text { TLcontext } 1\end{array}$ & R1 (e.g. however) \\
\hline & SLcontext2 & $\begin{array}{c}\text { Audience } 2> \\
\text { TLcontext2 }\end{array}$ & R2 (e.g. really) \\
\hline & SLcontextN & $\begin{array}{c}\text { AudienceN }> \\
\text { TLcontextN }\end{array}$ & $\begin{array}{l}\mathrm{RN} \text { (e.g. anyway, } \\
\text { after all, still etc.) }\end{array}$ \\
\hline
\end{tabular}

Figure 1. The translator as interpreter

$\mathrm{SL}=$ Source Language; $\mathrm{TL}=$ Target Language; $\mathrm{R}=$ representamen

The translator interprets the meaning of the SLrepresentamen in the SL context but there are a number of filters which will determine the TLrepresentamen which is ultimately selected: these include the factors mentioned by Nord (1997: 59-62): the intended function of the text and the function of the translation, the medium in which the translation is delivered (translations are generally written even though the original texts were spoken, subtitlers may attempt to capture at least some of the spoken quality of the original but are subject to pressures of space and may tone down over-colloquial language and swear-words which may be less acceptable in the written form), the time, place and intended audience (which might include the commissioner as well as the ultimate consumer).

What is more, in addition to variation depending on audience and changing TL contexts, the SLrepresentamen $\neq$ TLrepresentamen 1 or TLrepresentamen $2 / 3 / \mathrm{N}$, the TLrepresentamen can only be a 'best fit', as there is rarely a one-to-one correspondence between an SL and a TLrepresentamen, the two representamens will have, at the very least, different cultural correspondences (think of bread/Brot/ pain).and different polysemies (think of way/Weise/ mode).

Synchronic translation variability captures some of the polysemy and complexity of the single representamen quand même but also captures its untranslatability. Diachronic translation variability may indicate change in progress but it may reflect changes in TLrepresentamens (as indicated by Lehiste 1999). 


\section{Conclusions}

This chapter set out to investigate semantic change, weighing up the merits of two theoretical and methodological positions with respect to the analysis of the meaning of pragmatic markers: the core meaning + contextual side-effects approach versus the polysemy 'coded meaning' approach. It also hoped to evaluate the usefulness of parallel corpora in the analysis of semantic change.

Despite the limitations invoked with respect to the lack of synonymy between the SL and TLrepresentamens, I think it fair to say that the case study on the translation equivalence of quand même reveals that it is synchronically polysemous. In the contexts in which quand même is translated either through a zero translation, or by using intensifying, hedging or reformulating expressions, it could not have been translated using canonically adversative or concessive terms such as however or nonetheless. This suggests that a strictly minimalist approach (in casu the $P$ mais quand même $Q$ unifying analysis) cannot capture the evolving functions of pragmatic markers in a sufficiently fine-grained way to account for and explain semantic change.

The parallel corpus approach has allowed us to explore:

- Semantic bleaching (in the zero translations);

- Different functions of a term: adversative or relational;

- The proportion of these functions according to genre.

It is important to highlight the fact, however, that:

- The translation may be erroneous or idiosyncratic.

- Translations are, in any case, a 'best-fit' - there is seldom a one-to-one correspondence between lexical items in L1 and L2.

- Zero translations are ambiguous - are the SL forms desemanticised or has the translator simply been negligent in omitting them?

- Translations are a particular type of text which reflect translation practices and which have a tendency towards more conservative or canonical translations than might be the norm in SL texts (see Johansson, 1998:13-18, on the Norwegian particle nok).

- Many translations are possible - and the contextual interpretation may lead to 'non-type' PCIs such as that illustrated in Example (6) where quand même is translated as planned.

- Pragmatic ambiguity may be retained in translation equivalence: a GCI conventionally conveying indirectness, for example, can be derived from terms 
with similar literal or canonical core senses in L1 and L2 (as we have seen in Example (11) where quand même is translated though).

- The L1 term may be polysemous - but so, too, may the L2 term. Which of the many possible senses of the range of L2 terms should we read as the interpretation of the L1 term?

With particular reference to quand même and the possibility of exploring the semantic evolution of pragmatic markers more generally through translation equivalence, there is the specific problem of the lack of translated spontaneous colloquial language. Pragmatic markers are known to be characteristic of the spoken language and to appear far more rarely in written text. One of the best resources might appear to be film subtitles but film scores are generally scripted and writers rarely include pragmatic markers.

Parallel corpora can, however, complement evidence gathered from other sources - and translations have the decided advantage of combining insights from a number of different interpreters of meaning, engaged in authentic communicative behaviour.

\section{Corpora consulted}

\section{Spoken}

ESLO (1966-1970) Enquête Sociolinguistique d'Orléans - 109 hours of spoken French (902,755 words transcribed) $<$ http://bacharts.kuleuven.ac.be/elicop>

BC (1988) Beeching Corpus - 17.5 hours of spoken French, 155,000 words transcribed, 95 speakers.

<http://www.uwe.ac.uk/hlss/llas/iclru/corpus.pdf>

CRFP (2002) Corpus de Référence du Français Parlé - 40 towns in France, 400,000 words. Available via a concordancer at $<$ http://sites.univ-provence,fr/delic/corpus/index.html>

CFPP (2000-) Corpus du Français Parlé Parisien - 28 speakers, 36.6 hours of spoken interviews, transcribed and available.

$<$ http://cfpp2000.univ-paris3.fr/>

\section{Written}

FRANTEXT - literary corpus: 210 million words in 3,737 texts from the 16th. to the 21 st. century. Subscription only. <http://www.frantext.fr/> 


\section{Parallel corpora}

INTERSECT - 1.5 million words in French and English; 800,000 words in German and English (Raf Salkie, University of Brighton)

$<$ http://arts.brighton.ac.uk/staff/raf-salkie/portfolio-of-major-works/intersect>

European Parliament Corpus (1998-2009) - The Europarl parallel corpus is extracted from the proceedings of the European Parliament. It includes versions in 11 European languages: Romanic (French, Italian, Spanish, Portuguese), Germanic (English, Dutch, German, Danish, Swedish), Greek and Finnish. <www.statmt.org/europarl/>

OPUS (Sub-titled films). <http://opus.lingfil.uu.se/>

\section{Secondary sources}

Aijmer, K. 2002. English Discourse Particles. Evidence from a Corpus [Studies in Corpus Linguistics 10]. Amsterdam: John Benjamins.

Aijmer, K. 2007. Translating discourse particles: A case of complex translation. In Incorporating Corpora. The Linguist and the Translator, G. Anderman \& M. Rogers (eds), 95-116. Clevedon: Multilingual Matters.

Aijmer, K. \& Simon-Vandenbergen, A.-M. 2003. The discourse particle well and its equivalents in Swedish and Dutch. Linguistics 41: 1123-1161.

Aijmer, K., Foolen, A. \& Simon-Vandenbergen, A.-M. 2006. Pragmatic markers in translation: A methodological proposal. In Approaches to Discourse Particles, K. Fischer (ed.), 101-114. Amsterdam: Elsevier.

Anderman, G. \& Rogers, M. (eds). 2008. Incorporating Corpora. The Linguist and Translator. Clevedon: Multilingual Matters.

Beeching, K. 2005. Politeness-induced semantic change: The case of quand même. Language Variation and Change 17(2): 1-26.

Beeching, K. 2009. Procatalepsis and the etymology of hedging and boosting particles. In Current Trends in Diachronic Semantics and Pragmatics [Studies in Pragmatics 7], M.-B. Mosegaard Hansen \& J. Visconti (eds), 81-110. Bingley: Emerald.

Brinton, L. 1996. Pragmatic Markers in English. Grammaticalisation and Discourse Functions. Berlin: Mouton de Gruyter.

Dyvik, H. 1998. A translational basis for semantics. In Corpora and Cross-linguistic Research. Theory, Method and Case Studies, S. Johansson \& S. Oksefjell (eds), 51-86. Amsterdam: Rodopi.

Evans, N. \& Wilkins, D. 2000. In the mind's ear: The semantic extensions of perception verbs in Australian languages. Language 76(3): 546-592.

Granger, S., Lerot, J. \& Petch-Tyson, S. (eds). 2003. Corpus-based Approaches to Contrastive Linguistics and Translation Studies. Amsterdam: Rodopi.

Grice, H. P. 1975. Logic and conversation. In Syntax and Semantics, Vol. 3: P. Cole \& J. L. Morgan (eds), 41-58. New York NY: Academic Press.

Grieve, J. 1996. Dictionary of Contemporary French Connectors. London: Routledge.

Guillot, M.-N. 2010. Film sub-titles from a cross-cultural pragmatics perspective: Issues of linguistic and cultural representation. The Translator 16(1): 67-92.

Hansen, M.-B. Mosegaard. 1998. The Function of Discourse Particles. A Study with Special Reference to Spoken Standard French. Amsterdam: John Benjamins. 
Hansen, M.-B. Mosegaard. 2008. Particles at the Semantics/Pragmatics Interface: Synchronic and Diachronic Issues. A Study with Special Reference to the French Phasal Adverbs. Oxford: Elsevier.

Hansen, M.-B. Mosegaard \& Waltereit, R. 2006. GCI theory and language change. Acta Linguistica Hafniensa 38: 235-268.

Johansson, S. 1998. On the role of corpora in cross-linguistic research. In Corpora and Crosslinguistic Research. Theory, Method and Case Studies, S. Johansson \& S. Oksefjell (eds), 3-24. Amsterdam: Rodopi.

Lehiste, I. 1999. Successive translations as a source of evidence for linguistic change. International Journal of the Sociology of Language 139: 39-48.

McLaughlin, M. 2011. Syntactic Borrowing in Contemporary French. A Linguistic Analysis of News Translation. Oxford: Legenda.

Moeschler, J. \& de Spengler, N. 1981. Quand même: De la concession à la réfutation. Cahiers de Linguistique Française 2: 93-112.

Nord, C. 1997. Translating as a Purposeful Activity. Functionalist Approaches Explained. Manchester: St. Jerome.

Olohan, M. 2004. Introducing Corpora in Translation Studies. London: Routledge.

Oxford-Hachette French Dictionary. 1994. M.-H. Coorréard \& V. Grundy (eds). Oxford: OUP.

Peirce, C. S. 1931-35. Collected papers, Vols. 1-6, C. Hartshorne \& P. Weiss (eds). Cambridge MA: Harvard University Press.

Peirce, C. S. 1958. Collected papers, Vols. 7-8, A.W. Burkes (ed.). Cambridge MA: Harvard University Press.

Salkie, R. 1992. INTERSECT: Parallel corpus and contrastive linguistics. <http://bank.rug.ac.be/ contragram/newstell.html\#INTERSECT>

Sweetser, E. 1990. From Etymology to Pragmatics. Metaphorical and Cultural Aspects of Semantic Structure. Cambridge: CUP.

Tiedemann, J. 2009. News from OPUS - A collection of multilingual parallel corpora with tools and interfaces. In Recent Advances in Natural Language Processing, Vol. 5 [Current Issues in Linguistic Theory 309], N. Nicolov, K. Bontcheva, G. Angelova \& R. Mitkov (eds), 237-248. Amsterdam: John Benjamins.

Traugott, E. Closs \& Dasher, R. B. 2002. Regularity in Semantic Change. Cambridge: CUP.

Van Hoeke, W. \& Goyen, M. 1990. Translation as a witness to semantic change. Belgian Journal of Linguistics 5: 109-131. 


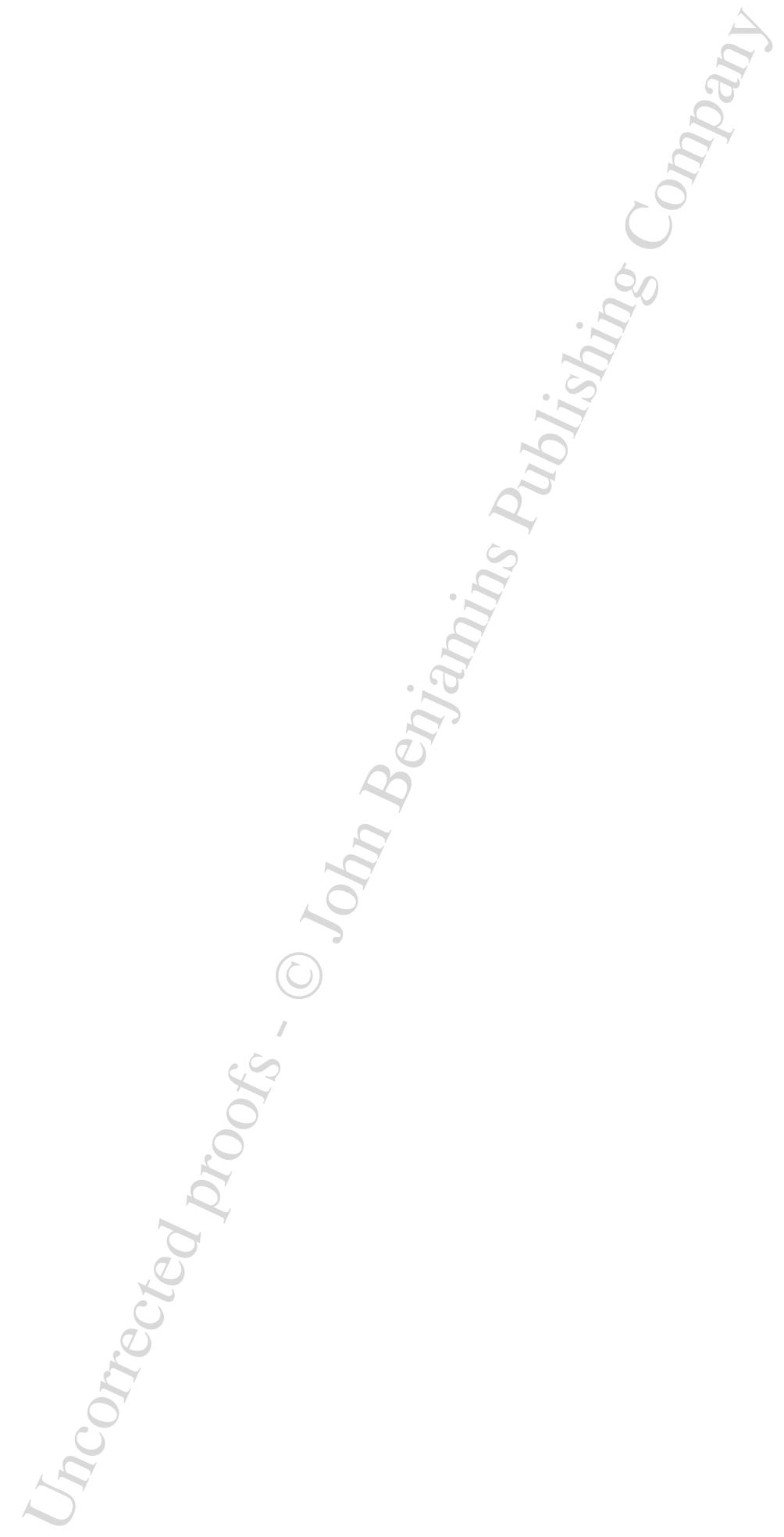

